\title{
Biomarkers: A Critical Update
}

\author{
Promod Kr Rathore ${ }^{1}$, Anoop Bhushan ${ }^{2}$, Sharnamma B ${ }^{3}$, Shweta Bali ${ }^{4}$, \\ Poonam Dutt ${ }^{5}$ \\ ${ }^{I}$ (Sr. lecturer, Dept. of Periodontics, Shree Bankey Bihari Dental college, Ghaziabad, U.P., India) \\ 2 (Professor and Head, Dept. of Periodontics, Santosh Dental College and Hospital, Ghaziabad, U.P., India) \\ ${ }^{3}$ (Professor and Head, Dept. of Periodontics, Shree Bankey Bihari Dental college, Ghaziabad, U.P., India) \\ ${ }^{4}$ (Professor, Dept. of Periodontics, Santosh Dental College and Hospital, Ghaziabad, U.P., India) \\ ${ }^{5}$ (Reader, Dept. of Periodontics, Shree Bankey Bihari Dental college, Ghaziabad, U.P., India)
}

\begin{abstract}
Periodontitis is a group of inflammatory diseases that affect the connective tissue attachment and supporting bone around the teeth. Early diagnosis and treatment of progressive periodontitis is important because of the irreversible nature of this disease. Biochemical mediators in oral fluids like saliva and gingival crevicular fluid $(G C F)$ are highly beneficial in the determination of current periodontal status. This article highlights recent advances in the use of biomarker-based disease diagnostics that focus on the identification of active periodontal disease from $G C F$, and saliva.
\end{abstract}

Key Words: Biomarkers, Gingival crevicular fluid, Diagnosis, saliva, Periodontal disease

\section{Introduction}

Periodontal disease is a chronic microbial infection that triggers inflammation-mediated loss of the periodontal ligament and alveolar bone that supports the teeth(1). Although periodontal diseases are initiated by bacterial pathogens, it is the activation and mediation of host inflammatory responses that are ultimately responsible for the destructive events occurring in the periodontium. Studies of the host immune response to pathogenic bacteria have contributed to the current understanding of the pathogenesis of periodontal diseases(2).

A goal of periodontal diagnostic procedures is to provide useful information to the clinician regarding the present periodontal disease type, location, and severity. These findings serve as a basis for treatment planning and provide essential data during periodontal maintenance and disease-monitoring phases of treatment.

Traditional periodontal diagnostic parameters used clinically include probing depths, bleeding on probing, clinical attachment levels, plaque index, and radiographs assessing alveolar bone levels(3). The strengths of these traditional tools are their ease of use, their cost-effectiveness, and that they are relatively noninvasive. Traditional diagnostic procedures are inherently limited, in that only disease history, not current disease status, can be assessed. Clinical attachment loss readings by the periodontal probe and radiographic evaluations of alveolar bone loss measure damage from past episodes of destruction and require a 2- to 3-mm threshold change before a site can be identified as having experienced a significant anatomic event(4).

There is a need for the development of new diagnostic tests that can detect the presence of active disease, predict future disease progression, and evaluate the response to periodontal therapy, thereby improving the clinical management of periodontal patients. The diagnosis of active phases of periodontal disease and the identification of patients at risk for active disease represent challenges for clinical investigators and practitioners. This article highlights recent advances in the use of biomarker-based disease diagnostics that focus on the identification of active periodontal disease from gingival crevicular fluid (GCF), and saliva(5).

\section{Biomarkers}

Biomarkers may be defined as a substance that is measured objectively and evaluated as an indicator of normal biologic processes, pathogenic processes, and pharmacologic responses to a therapeutic intervention.

Biomarkers, whether produced by normal healthy individuals or by individuals affected by specific systemic diseases, are telltale molecules that could be used to monitor health status, disease onset, treatment response and outcome. Informative biomarkers can further serve as early sentinels of disease. Biomarkers of disease in succession play an important role in life sciences and have begun to assume a greater role in diagnosis, monitoring and therapy outcomes and drug discovery. The challenge for biomarkers is to allow earlier detection of disease evolution and more robust therapy efficacy measurements (Colburn 2003)(6).

Advances in oral and periodontal disease diagnostic research are moving toward methods whereby periodontal risk can be identified and quantified by objective measures such as biomarkers(Table1)(7). 
Table 1: Diagnostic tools to measure periodontal disease at the molecular, cellular, tissue, and clinical levels.

\begin{tabular}{|c|c|c|}
\hline Level & Example of process & Example of diagnostic tools \\
\hline Molecular & $\begin{array}{l}\text { Activation of receptors for endotoxin: } \\
\text { CD-14; Toll-like receptors }\end{array}$ & $\begin{array}{l}\text { Polymerase chain reaction; DNA- } \\
\text { DNA hybridization; laser-capture } \\
\text { microdissection }\end{array}$ \\
\hline Cellular & $\begin{array}{l}\text { Inflammatory cell activation such as } \\
\text { neutrophils; osteoclast activation }\end{array}$ & ELISA; immunohistochemistry \\
\hline Tissue & $\begin{array}{l}\text { Downgrowth of junctional epithelium; } \\
\text { bone and connective tissue loss }\end{array}$ & $\begin{array}{l}\text { Histomorphometry; } \\
\text { immunohistochemistry }\end{array}$ \\
\hline \multirow[t]{2}{*}{ Clinical } & Attachment loss & Periodontal probing \\
\hline & Bone loss & Radiographs \\
\hline
\end{tabular}

\section{Classification Of Biomarker From Gcf And Saliva}

Recent advances in the use of biomarker based diagnostics for disease activity include mediators that are released into GCF \& saliva can be broadly grouped according to their sources(5).

1) Microbial Plaque: Endotoxins (lipopolysachrides), Enzymes, Metabolic end products, DNA probes, Cultures of putative periodontal pathogens.

2) Host Derived :- 1L- $\beta$, Aspartate, Aminotransferase, Transferase, Matrix proteins, Lactoferrin, Lysozyme etc.

3) Connective Tissue Breakdown Products: Collegen-telopeptides, Osteocalcin, Proteoglycans, Breakdown products, Fibronectin fragments.

4) Inflammatory Mediators: Complement, Cytokines, Interleukins, Tumor necrosis factor- $\alpha$, Interferon- $\alpha$, Antibacterial Antibodies IgG, IgM, IgA, Substance P, Prostaglandin E2, Acute-phase proteins, transferrin, Creactive protein.

\section{Biomarker For Periodontal Disease}

Specific salivary biomarkers for periodontal disease, which are considered to be the mirror of the body are enlisted below (Table 2)(8).

Table 2

\begin{tabular}{|c|c|c|c|}
\hline Proteomic Biomarkers & Genetic Biomarker & Microbial Biomarker & Other Biomarker \\
\hline $\begin{array}{l}\text { Cystatins, } \alpha \text {-glucosidase, } \\
\text { Acid phosphatise, } \\
\text { Alkaline phosphatise, Aminopeptidase, } \\
\text { Lactoferrin, Translactoferin, IgM, MMP-13, } \\
\text { MMP-8, MMP-9, Cathepsin B, Osteonectin, } \\
\text { Osteocalcin, Osteopontin, Osteopontin, Elastase } \\
\text { Platelet-activating factor, Epidermal growth } \\
\text { factor, Platelet-derived growth factor, Esterase, } \\
\text { Pyridinoline crosslinked carboxyterminal } \\
\text { telopeptide, } \\
\text { Fibronectin,sIgA(secretory IgA) Gelatinase, } \\
\text { IgA, Trypsin, Vascular endothelial growth } \\
\text { factor, IgG }\end{array}$ & $\begin{array}{l}\text { Cathepsin C gene } \\
\text { Mutation, } \\
\text { Collagen gene } \\
\text { mutation, } \\
\text { IL-1 } \\
\text { polymorphisms, } \\
\text { IL-10 } \\
\text { polymorphisms, } \\
\text { Tumor necrosis } \\
\text { factor, } \\
\text { Polymorphisms. }\end{array}$ & $\begin{array}{l}\text { Aggregatibacter } \\
\text { Actinomycetemcomitans, } \\
\text { Campylobacter rectus, } \\
\text { Mycoplasmas, } \\
\text { Porphyromonas Gingivalis, } \\
\text { Prevotella intermedia, } \\
\text { Peptostreptococcus } \\
\text { Micros, } \\
\text { Prevotella nigrescens, } \\
\text { Treponema denticola, } \\
\text { Tannerella forsythia. } \\
\text { Treponema socranskii. }\end{array}$ & $\begin{array}{l}\text { Calcium, } \\
\text { Cortisol, } \\
\text { Hydrogen sulphide, } \\
\text { Methylmercaptan, } \\
\text { Methylmercaptan, } \\
\text { Methylmercaptan, } \\
\text { Pyridine. }\end{array}$ \\
\hline
\end{tabular}

\section{Diagnostic Tools( Commercially Available)}

Only a few of the enzymes described above appear to be actively predictive of disease activity. Therefore the evaluation of some of the recently used biomarkers and some under developmental stage are shown below in Table 3(9).

Table 3

\begin{tabular}{|l|l|l|l|}
\hline & Assay & Diagnostic kit & Critical Evaluation \\
\hline 1 & $\begin{array}{l}\text { Culture } \\
\text { biochemical } \\
\text { Identification (GOLD } \\
\text { STANDARD) }\end{array}$ & Laboral & $\begin{array}{l}\text { It is highly technique sensitive \& time consuming. But it can be used for testing } \\
\text { against resistant pathogens. Pathogens of secondary importance can also } \\
\text { reported if found in high percentage. }\end{array}$ \\
\hline 2 & $\begin{array}{l}\text { Bacterial enzymes \& } \\
\text { host enzymes }\end{array}$ & $\begin{array}{l}\text { BANA(benzoyl-DL- } \\
\text { arginine- } \beta- \\
\text { napthylamide) }\end{array}$ & $\begin{array}{l}\text { Pathogens like T. d, B. f, P. g can be detected. With 90-96\% sensitivity, 83- } \\
92 \% \text { specificity. But A. a can't be detected; using BANA. } \\
\text { Clinical studies have shown the usefulness of BANA hydrolytic activity, the } \\
\text { presence of which is significantly correlated with pocket probing depths and } \\
\text { attachment loss greater than 4 mm. The number of BANA-positive sites } \\
\text { observed in periodontitis patients decreases after successful therapy comprising } \\
\text { scaling, root planning and administration of systemic antibiotics. } \\
\text { Both periocheck \& perioscan were not very successful \& some are no longer } \\
\text { distributed. }\end{array}$ \\
\hline
\end{tabular}




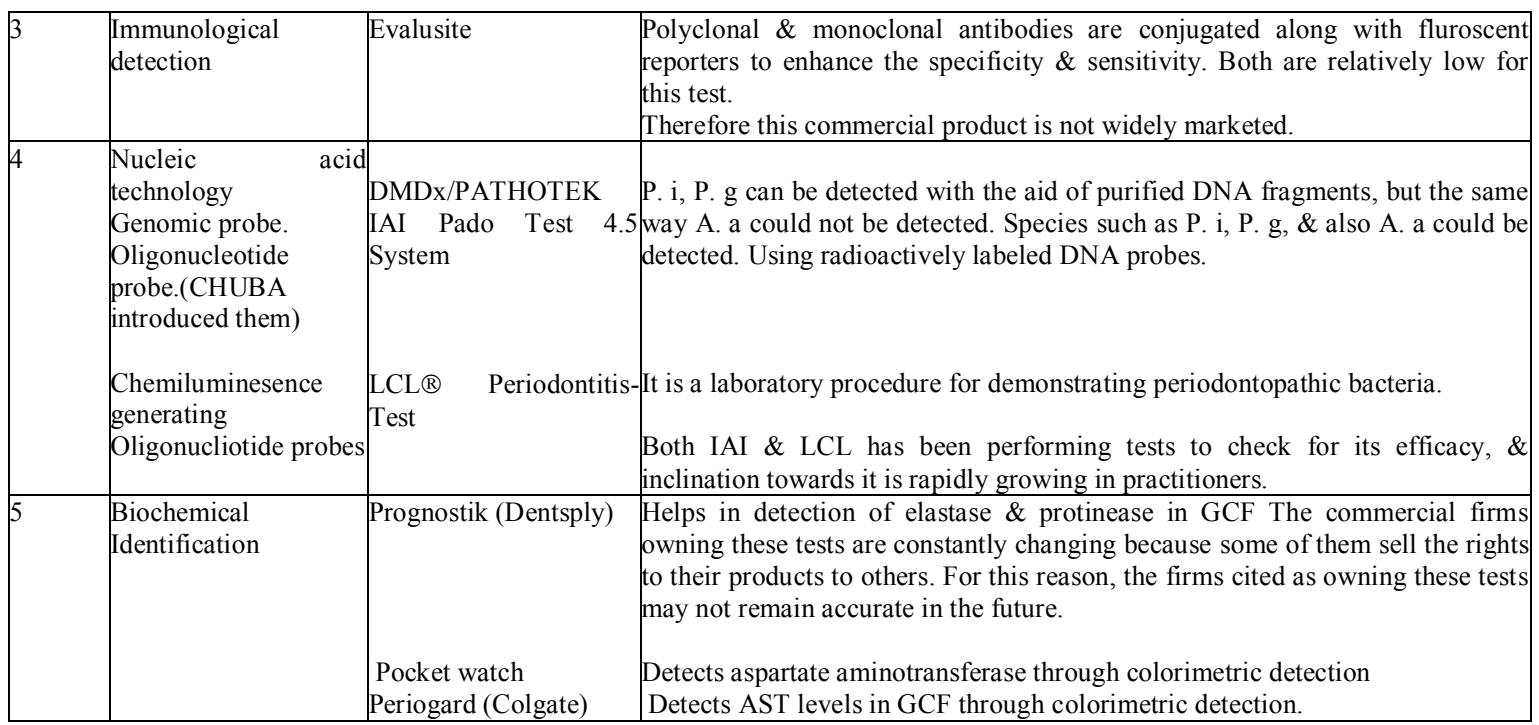

A.a: Aggregatibacter actinomycetemcomitans, B.f: Bacteroids forsythus, C.r: Campylobacter rectus, E.c: Eikenella corrodens, P.m: Peptostreptococcus micros, P.g: Porphyromonas gingivalis, P.i: Prevotella intermedia, P.d: Prevotella denticolla, T.d: Treponema denticola.

\section{Current Concepts}

A tremendous amount of research activity is currently under way to explore their role as a possible medium in a variety of applications. There are quite a few commercial diagnostic kits under practice such as

- $\beta$ - glucuronidase: Abbott laboratories (U.S.A), dentoAnalyzer is among the first quantitative MMP-8 chairside testing devices in periodontal and peri-implant diagnostics and research.

- Immunofluorometric assay and dento-analyzer can detect MMP-8 from GCF samples.

- Electrochemical biosensors coupled to Magnetic Beads are also used for the Detection of Clinical Biomarkers.

Also several researchers have focused on genetic single nucleotide polymorphisms in the study of periodontitis. There is a genetic susceptibility test currently available for severe chronic periodontitis (Interleukin Genetics, Waltham. Massachusetts). Individuals identified as "genotype positive," are more likely to have the phenotype of overexpression of this gene(9).

$\mathrm{Li}$ et al. investigated the potential use of genomics in the development of salivary diagnostics. They performed microarray testing of cell-free saliva for RNA profiling. RNA was isolated from unstimulated saliva that was collected from healthy subjects. After analysis by microarray and quantitative polymerase chain reaction, they found that it was possible to profile messenger RNAs, of which there were thousands present in the saliva. More recently, the group demonstrated the potential of salivary IL-8 levels to predict whether the patient was affected with squamous cell carcinoma(10).

\section{Nucleic Acid Probes}

In recent years, DNA probes have been developed to identify nucleotide sequences that are specific for individual bacterial species, believed to be of diagnostic significance. DNA and RNA probes are available Fig1(11). 


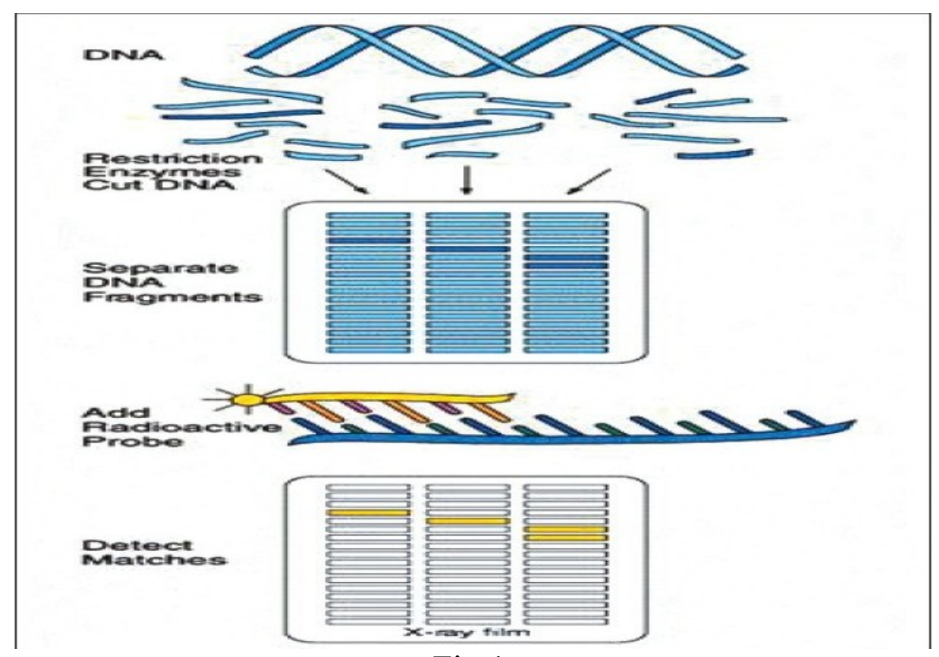

Fig.1

\section{Infrared Spectroscopy}

Compared to analyzing one or more particular biomarkers in the tissue or body fluid, infrared (IR) spectroscopy analyzes complex biologic systems by capturing the entire IR spectrum that represents the sum of the contributions of the biomolecules present, such as proteins, lipids, sugars, and nucleic acids. The IR spectrum of GCF is a rich source of information regarding the oral cavity and associated inflammation.

IR spectroscopy can distinguish between the characteristics of diverse molecules by probing vibrations of chemical bonds and can use these molecular and submolecular profiles to define and differentiate between diseased and healthy tissues.

IR analysis of GCF, unlike traditional biochemical analyses, measures the total contents of GCF and may prove to be a more powerful diagnostic and prognostic tool for periodontal diseases. Subtle differences in the spectral band intensity and positions arising from the three major components, i.e., lipid, protein and DNA, were observed in GCF from healthy, gingivitis, and periodontitis groups.

\section{Near-IR spectroscopy}

Near-IR (NIR) spectroscopy can be used to monitor hemodynamic and edema-based markers of soft tissues of the oral cavity. Several light-absorption bands in the visible and NIR spectral region reflect key inflammatory events. The 500- to 600 -nm wavelength region is dominated by the absorption from oxygenated hemoglobin $\left(\mathrm{HbO}_{2}\right)$ and deoxygenated hemoglobin $(\mathrm{Hb})$ in the capillary bed gingival tissue, whereas the absorption from water results in an increased attenuation at longer wavelengths centered at $970 \mathrm{~nm}$. In addition, tissue edema, an index that is commonly used as a marker of gingival inflammation, can be measured using NIR spectroscopy(12).

\section{Future Trends}

A tremendous amount of research activity is currently under way to explore the role of oral fluids as a possible medium in a variety of applications.

Recent advances in HIV diagnosis have been made using oral fluids. A commercially available kit (OraSure, OraSure Technologies, Bethlehem, Pennsylvania) has an oral specimen collection device that is placed between the buccal mucosa and buccal gingiva for 2 to 5 minutes to collect HIV-1 antibodies (not the virus) from the tissues of the cheek and gingiva. OraSure HIV-1 does not collect saliva but rather a sample called oral mucosal transudate(13).

Researchers in the biotechnology and medical realm are currently investigating the use of oral fluids for the diagnosis of oral and systemic diseases and for drug development. In the pharmaceutical industry, the use of biomarkers is avidly being developed for use in tailored dosing and drug metabolism studies. Professionals in seemingly unrelated arenas such as the insurance industry, the Environment Protection Agency, and Homeland Security are interested in the possible use of oral fluids to monitor biomarkers. Under investigation are possible uses of GCF and saliva in the preliminary screening for biological/chemical warfare agent exposure, environmental toxin detection, and screening for metabolites of drugs of abuse(5).

Moreover, technologies such as nucleic acid and protein microarrays and microfluidics are under development for risk assessment and comprehensive screening of biomarkers. These recent advances are leading to the development of more powerful diagnostic tools for practitioners to optimize their treatment predictability(9). 
In the future, mini molecular laboratories will be available for chair-side DNA probe testing in an hour or less (Periodontal Microbial Identification Test, Saigene Corp, Bothell, WA, USA). However, the advice of a microbiologist might still sometimes be necessary to avoid problems that may occur in the diagnostic $\operatorname{process}(11)$.

GCF contains elevated levels of a vast array of biochemical factors which offer us proper diagnosis of disease activity. The future method of GCF analysis is shown in Fig 2(11).

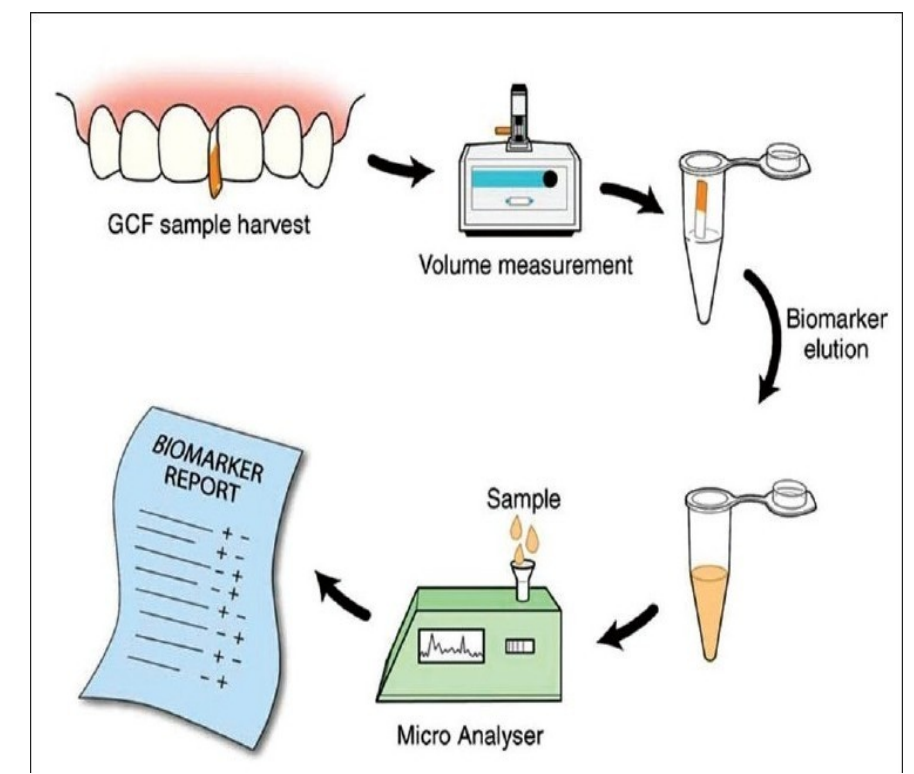

Fig 2

\section{Conclusion}

From physical measurements such as periodontal probing to sophisticated genetic susceptibility analysis and molecular assays for the detection of biomarkers on the different stages of the disease, substantial improvements have been made on the understanding of the mediators implicated on the initiation and progression of periodontitis.

These recent advances are leading to the development of more powerful diagnostic tools for practitioners to optimize their treatment predictability.

The future is bright for the use of rapid, easy-to-use diagnostics that will provide an enhanced patient assessment that can guide and transform customized therapies for dental patients, leading to more individualized, targeted treatments for oral health.

\section{References}

[1] Albandar JM, Brunelle JA, Kingman A. Destructive periodontal disease in adults 30 years of age and older in the United States, 1988-1994. J Periodontol 1999; 70:13-29.

[2] Offenbacher S, Barros S, Mendoza L, et al. Changes in gingival crevicular fluid inflammatory mediator levels during the induction and resolution of experimental gingivitis in humans. J Clin Periodontol 2010;37:324-33.

[3] Armitage GC. The complete periodontal examination. Periodontol 2000. 2004;34:22-33.

[4] Goodson JM. Conduct of multicenter trials to test agents for treatment of periodontitis. J Periodontol. 1992;63:1058-63.

[5] Taba M, Kinney J, Kim AS et al. Diagnostic Biomarkers for Oral and Periodontal Diseases. Dent Clin North Am. 2005 July; 49(3): 551-vi.

[6] Colburn WA . Biomarkers in drug discovery and development: from target identification through drug marketing. Journal of Clinical Pharmacology,2003, 43(4):329-41.

[7] Frodge BD, Ebersole JL, Kryscio RJ, et al. Bone Remodeling Biomarkers of Periodontal Disease in Saliva. J Periodontol. 2008;79:1913-19.

[8] Zhang L et al. The clinical value of salivary biomarkers for periodontal disease. Periodontology 2000; 2009: 51:25-37.

[9] Reddy S, Kaul S, Prasad M.G.S. Biomarkers in Periodontal Diagnosis: "What The Future Holds..."int. journal of clinical dental science $\cdot$ february, $2011 \cdot 2(1)$.

[10] Li Y, Zhou X, John MA, et al. RNA profiling of cell-free saliva using microarray technology. J Dent Res. 2004;83(3):199-203.

[11] Khiste SV, Ranganath V, Nichani AS et al. Critical analysis of biomarkers in the current periodontal practice. J Indian Soc Periodontol. 2011 Apr-Jun; 15(2): 104-10.

[12] Xiang X, Sowa MG, Iacopino AM et al. An Update on Novel Non-Invasive Approaches for Periodontal Diagnosis. J Periodontol. 2010;81:186-98.

[13] Reynolds SJ, Muwonga J. OraQuick advance Rapid HIV-1/2 antibody test. Expert Rev Mol Diagn. 2004;4(5):587-91. 